\title{
EXPERIMENTAL INVESTIGATION OF SOME MECHANICAL PROPERTIES OF RUBBERIZED CONCRETE WITH HIGHEST POSSIBLE RUBBER CONTENT
}

\author{
Wrya A. Abdullah ${ }^{1}$, Muhammad A. Muhammad' and Mohamed R. AbdulKadir \\ Dept. of Civil Engineering, College of Engineering, University of Sulaimani, \\ Kurdistan Region-Iraq
}

(Accepted for Publication: December 8, 2020)

\begin{abstract}
Each year more than a billion tires are discarded globally, millions of them are disposed to landfills especially in the developing countries which leads to serious environmental issues. This paper experimentally investigates mechanical properties of concrete containing highest possible ratio of recycled tire rubber content as fine aggregate replacement in terms of compressive strength, workability, dry and fresh densities. For this purpose, eleven different concrete mixes were cast with various sand replacement ratios by mass from $0 \%$ to $60 \%$ with increments of $6 \%$. Three cubic specimens from each mix were cast and tested to measure the mechanical properties at the age of 28 days. All the specimens had the water-cement ratio and curing period without using any admixtures. It is concluded that the workability, density, and compressive strength of the rubberized concrete samples are significantly reduced with an increase of the rubber content. Moreover, it is observed that the mix becomes stiff and non-workable beyond $60 \%$ of rubber content. Furthermore, the test results are compared with non-rubberized concrete (control mix) and the available data on rubberized concrete from the literature. Finally, equations for predicting the aforementioned properties are derived.
\end{abstract}

KEYWORDS: Rubberized Concrete; Concrete Density; Workability; Compressive Strength; Recycled Tire Rubber Aggregate

\section{INTRODUCTION}

D isposal management of waste vehicle tires has been a main issue to the municipalities worldwide. Nearly a billion tire was estimated to be useless annually in 2007 (Colom et al., 2007). This number will reach its peak in 2030 as the estimations point to 5 billion tires to be out dated including the stockpiles (Pacheco-Torgal et al., 2012). After the recent great concern on the climate change, reduction of the environmental impacts interested the researchers all around the globe. Dumping waste wrya.faraj@univsul.edu.iq; mohamed.abdulkadir@univsul.edu.iq

${ }^{1}$ Corresponding author: College of Engineering, University of Sulaimani, Kurdistan Region, Iraq tires to the landfills leads to the environmental pollution. The uncontrolled fires frequently rise from these fields resulting in hazardous gas release (Downard et al, 2015). This method of material disposal is unfavorable and it is legally prohibited in some states in the United States of America (Rubber Manufacturers Association, 2018), and in some of the countries in European Union (EU, 1999). Therefore, reusing disposed tires seems to be essential by means of pioneering methods. Reusing waste tires in building constructions can be a positive technique of managing these wastes instead of muhammad.rashid@univsul.edu.iq; 
landfilling. The scrap tires can be utilized in forms of rubber chips in concrete as replacements for coarse or fine aggregates. This replacement method has gained attention amongst researchers in the past decades, however, only a few researchers in Kurdistan region of Iraq started working in this research area.

The main characteristics of concrete to be tested are mechanical properties and physical properties. Numerous research studies were carried out on rubberized concrete using random replacement ratios. For example, Taha et al. (2008) investigated crumb rubber (size 5-1 mm) in concrete as fine aggregate replacement at $0 \%$, $25 \%, 50 \%, 75 \%$ and $100 \%$ by volume. They used a constant water cement ratio for all their mixes. They concluded that the workability, fresh density, dry density and compressive strength of rubberized concrete reduces with increasing the rubber content. The reduction in the concrete workability with increasing the rubber content was also reported by Topçu and Demir (2007), Batayneh et al. (2008) and Ozbay et al. (2011). Some other studies revealed that fresh and dry density of concrete containing rubber chips as fine aggregate replacement decreases with an increase in the rubber content (Turki et al., 2009; Sukontasukkul and Tiamlom, 2012; Grdic' et al., 2014; Mohammadi et al., 2014). The compressive strength of the concrete is considered as the most interesting mechanical properties in rubberized concrete. It is proven that compressive strength considerably declines by elevating the level of rubber chip ratios (Torgut and Yesilata 2008; Atahan \& Yücel, 2012; Issa \& Salem, 2013). Looking at the literature, it can be seen that finding equations for predicting the compressive strength of the rubberized concrete with small increment ratios is rare.

The gap of the most of the studies found in the literature is that either they have not reached wrya.faraj@univsul.edu.iq; mohamed.abdulkadir@univsul.edu.iq a full replacement of the fine aggregate with rubber chips or they reached that limit but with huge gaps in between the replacement increment ratios. For instance, El-Gammal et al. (2010) carried out tests on rubberized concrete using only two replacement ratios of $50 \%$ and $100 \%$ by volume. Some other researchers used five intervals between $0 \%$ to $100 \%$ with $20 \%$ of increment to investigate the effects of rubber on the compressive strength (Khaloo et al., 2008). Therefore, the prediction of the equations correlating the rubber content with mechanical properties are limited with these large increments. The current work tries to study a wide range of rubber contents until a full fine aggregate replacement is achieved. It is part of an extensive project on investigation of concrete containing recycled tire rubber which involves fire exposure effect (Muhammad et al., 2017), high elevated temperature environments (Abdullah et al., 2018) and exposed to impact load with and without fire (Muhammad et al., 2020).

This paper reports an experimental investigation on the mechanical properties of normal concrete containing waste tire rubber chips. The concrete mixes were produced with a constant water cement ratio of 0.393 . The particle sizes of waste rubber chips ranges between (0-4.75) $\mathrm{mm}$ with eleven different replacement levels of $(0 \%, 6 \%, 12 \%, 18 \%, 24 \%$, $30 \%, 36 \%, 42 \%, 48 \%, 54 \%$, and $60 \%$ ) by sand mass. In the concrete's fresh state, the workability and wet density of the samples were measured. The hardened concrete samples were tested for compressive strength and their dry densities were measured.

\section{EXPERIMENTAL PROGRAM}

\subsection{Materials}

The main materials used in the concrete mixes of this study are cement, course and fine muhammad.rashid@univsul.edu.iq; ity of Sulaimani, Kurdistan Region, Iraq 
aggregate and water. All these materials are locally available in Sulaymaniyah city, Iraq. The general properties of main ingredients of the concrete are as following: First, the cement used for all mixes was an Ordinary Portland Cement (CEMI/42.5 R) and it was produced according to EN 197-1:2011. Secondly, the type of the fine aggregate used in this study was natural. The maximum particle size of the fine aggregate was $4.75 \mathrm{~mm}$ with saturated specific gravity of 2.59 . Thirdly, the source of the coarse aggregate was basalt based with the maximum size of $10 \mathrm{~mm}$. The shape of coarse aggregate was round naturally along with having the specific gravity of 2.64. The recycled tire rubber used was commercially available as infill for artificial turf fields and playgrounds. The maximum size of tire rubber in dry condition was $4.75 \mathrm{~mm}$. The other detail properties of the fine aggregate, coarse aggregate and rubber chips can be found in Table 1. As it can be seen in Table 1. The compacted dry density of the rubber chips was nearly half of fine aggregate's dry density and it was $677 \mathrm{~kg} / \mathrm{m}^{3}$.

Figure 1 shows particle size distribution of recycled tire rubber, coarse and fine aggregates. As the study focuses on using normal concrete; therefore, no additives or admixtures were used in preparing the mixes.

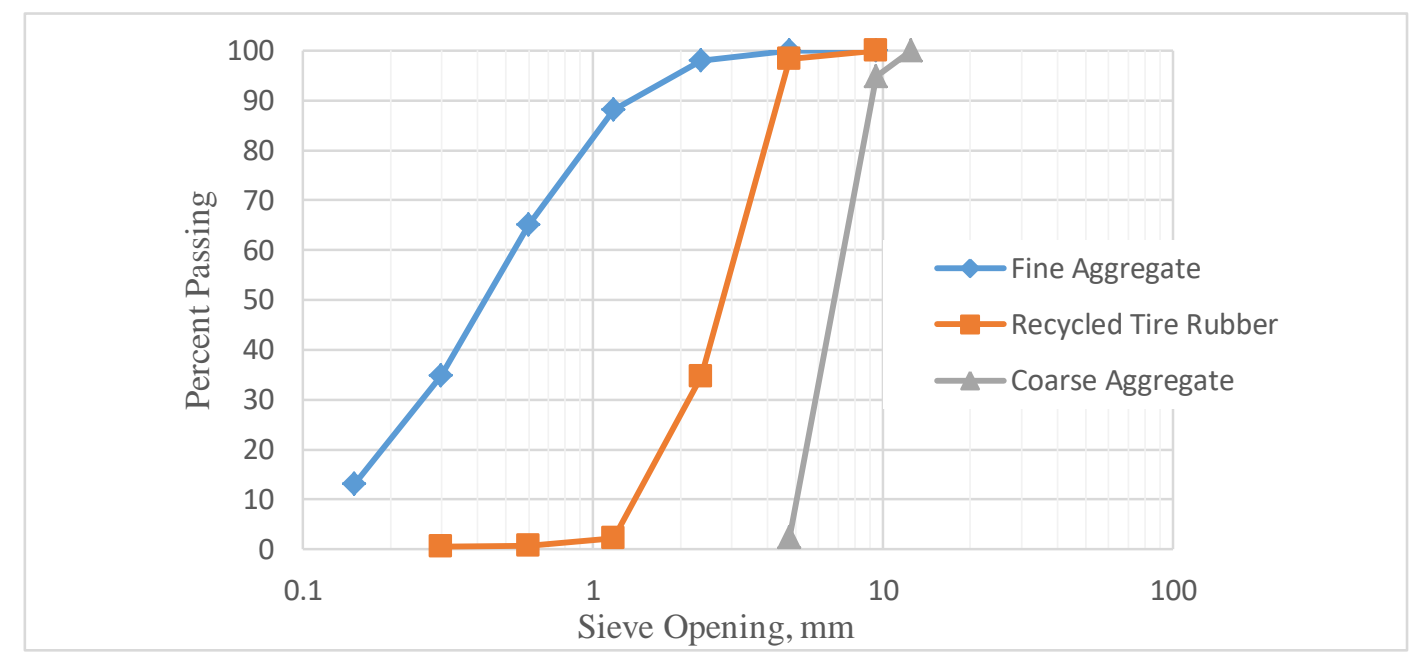

Fig. (1): Particle size distribution

Table (1): Tests on materials and materials

\begin{tabular}{lccc}
\hline \multicolumn{1}{c}{ Physical properties } & Coarse aggregate & Fine aggregate & Tire Rubber \\
\hline Fineness Modulus, unit less & 2.03 & 2.01 & - \\
\hline Max. particle size, $\mathrm{mm}$ & 10 & 4.75 & 4.75 \\
\hline Compact dry density, $\mathrm{kg} / \mathrm{m}^{3}$ & 1679 & 1552 & 677 \\
\hline Uncompact dry density, $\mathrm{kg} / \mathrm{m}^{3}$ & 1565 & 1322 & 576 \\
\hline Water absorption, \% & 0.96 & - & - \\
\hline The bulk specific gravity, Dry & 2.62 & 2.46 & - \\
\hline The bulk specific gravity, SSD & 2.64 & 2.59 & - \\
\hline The Apparent specific gravity & 2.68 & 2.84 & Round, dry \\
\hline Particle surface & Round & - & Grinding machine \\
\hline Source & River & River & \\
\hline
\end{tabular}

wrya.faraj@univsul.edu.iq; muhammad.rashid@univsul.edu.iq; mohamed.abdulkadir@univsul.edu.iq

${ }^{1}$ Corresponding author: College of Engineering, University of Sulaimani, Kurdistan Region, Iraq 


\subsection{Concrete Mix design}

The targeted controlled mix was designed to achieve the mean compressive strength of 40 $\mathrm{MPa}$ in accordance with ACI 211.1. Based on the mix design and physical properties of the ingredients, the predicted workability of the mix was the slump of $100-140 \mathrm{~mm}$. After designing the mix, the mix proportions obtained for one cubic meter of the concrete mix were (1:1.179:1.346) for cement, sand and gravel, respectively. Based on the targeted compressive strength, the water cement ratio was turned out to be 0.393 for all mixes.

After finishing the mixture design, eleven different mixes were produced. The first mix was used as a "control mix" which was made of pure concrete sample without rubber so it is referred to as having (0\%) rubber content. The other ten mixes have different rubber ratios as replacements of fine aggregates by mass starting from $6 \%$ replacement of the fine aggregate up to $60 \%$ with increments of $6 \%$. The highest possible rubber content in terms of workability was achieved at the level of $60 \%$ by mass. Because the density of the rubber is less than that of fine aggregate, the amount of tire rubber at $60 \%$ by mass is equivalent to $138 \%$ of sand by volume.

\subsection{Specimen Preparations}

In total, eleven mixes were prepared representing different replacements of fine aggregate with rubber aggregate of the same maximum size. The experimental variable was the replacement ratio which started with $0 \%$ (controlled mix) and the ratio increases with increments of $6 \%$ until reaching the highest possible level of $60 \%$ by mass. The main objective was to replace the fine aggregate with rubber until the mix reaches zero slump which was achieved at the replacement ratio of $60 \%$ by mass. Table 2 presents the calculated amounts of materials needed for one batch of a concrete mix with the volume of 0.008 cubic meter. From each mix, three individual specimens were made for performing the tests and for measuring the average test results

Table (2): Concrete mix proportions

\begin{tabular}{|c|c|c|c|c|c|c|}
\hline & Replacement, \% & Cement, kg & $\begin{array}{c}\text { Fine } \\
\text { Aggregate, } \\
\text { kg }\end{array}$ & $\begin{array}{c}\text { Coarse } \\
\text { Aggregate, } \\
\text { kg }\end{array}$ & $\begin{array}{c}\text { Water, } \\
\text { kg }\end{array}$ & $\begin{array}{c}\text { Tire } \\
\text { Rubber, } \\
\text { kg }\end{array}$ \\
\hline Mix 1 & 0 & 7 & 8.250 & 9.42 & 2.75 & 0 \\
\hline Mix 2 & 6 & & 7.755 & & & 0.495 \\
\hline Mix 3 & 12 & & 7.260 & & & 0.99 \\
\hline Mix 4 & 18 & & 6.765 & & & 1.485 \\
\hline Mix 5 & 24 & & 6.270 & & & 1.98 \\
\hline Mix 6 & 30 & & 5.775 & & & 2.475 \\
\hline Mix 7 & 36 & & 5.280 & & & 2.97 \\
\hline Mix 8 & 42 & & 4.785 & & & 3.465 \\
\hline Mix 9 & 48 & & 4.290 & & & 3.96 \\
\hline Mix 10 & 54 & & 3.795 & & & 4.455 \\
\hline Mix 11 & 60 & & 3.300 & & & 4.95 \\
\hline
\end{tabular}

wrya.faraj@univsul.edu.iq; muhammad.rashid@univsul.edu.iq; mohamed.abdulkadir@univsul.edu.iq 


\subsection{Tests of Specimens}

Several tests were carried out on the samples in both fresh and hardened concrete states. For each mix, the workability, wet density, dry density and compressive strength were obtained using three specimens. In the laboratory the mix batches were produced manually in a steel basin to ensure the uniformity of rubber particles distribution in the mix. The batch was prepared in this manner: Firstly, the sand and rubber aggregates were weighed and mixed in dry condition. Then, they were mixed together with coarse aggregate and the cement. Finally, the water was added to the batch and all ingredients mixed for about 5 minutes till a fresh concrete achieved. In its fresh state, the slump test was performed to record the workability of the concrete mix. After that the fresh concrete was poured into the molds. Cubic specimens of size of $150 \times 150 \times 150 \mathrm{~mm}$ were used for testing compressive strength at the end of 28-day curing period. The concrete was poured into the molds with two different layers. Each layer of the concrete was subjected to vibration on a shaking table machine for approximately 5 seconds. After the vibration, the fresh density of wet concrete was recorded by weighing the wet compacted cubes. After 28 days, the dry density of the samples was measured by weighing them before performing the compression test. Each test result was determined by taking the average of the results of three specimens.

\section{RESULTS AND DISCUSSIONS}

\subsection{Workability}

It has been found that the workability of rubberized concrete declines with an increase of rubber content. Figure 2 shows a slightly linear decrease in the slump from the maximum value of $140 \mathrm{~mm}$ at $0 \%$ rubber content to nearly zero slump at maximum rubber content of $60 \%$ by mass. It can be seen form Figure 2, that the workability remained almost unchanged or slightly changed in the samples that containing approximately $6 \%$ to $18 \%$ of rubber. Then the workability of the samples decreased rapidly until reaching the value of zero slump at $60 \%$ of the replacement. There is a point where the workability remains nearly unchanged for $30 \%$ and $36 \%$ of replacement. Almost similar pattern can be observed for any two successive ratios of $6 \%$ which might be an indication that the $6 \%$ of replacement by mass does not have a considerable effect on the workability of the mixes. However, if the increment ratio changes to $12 \%$ the difference would be more obvious.

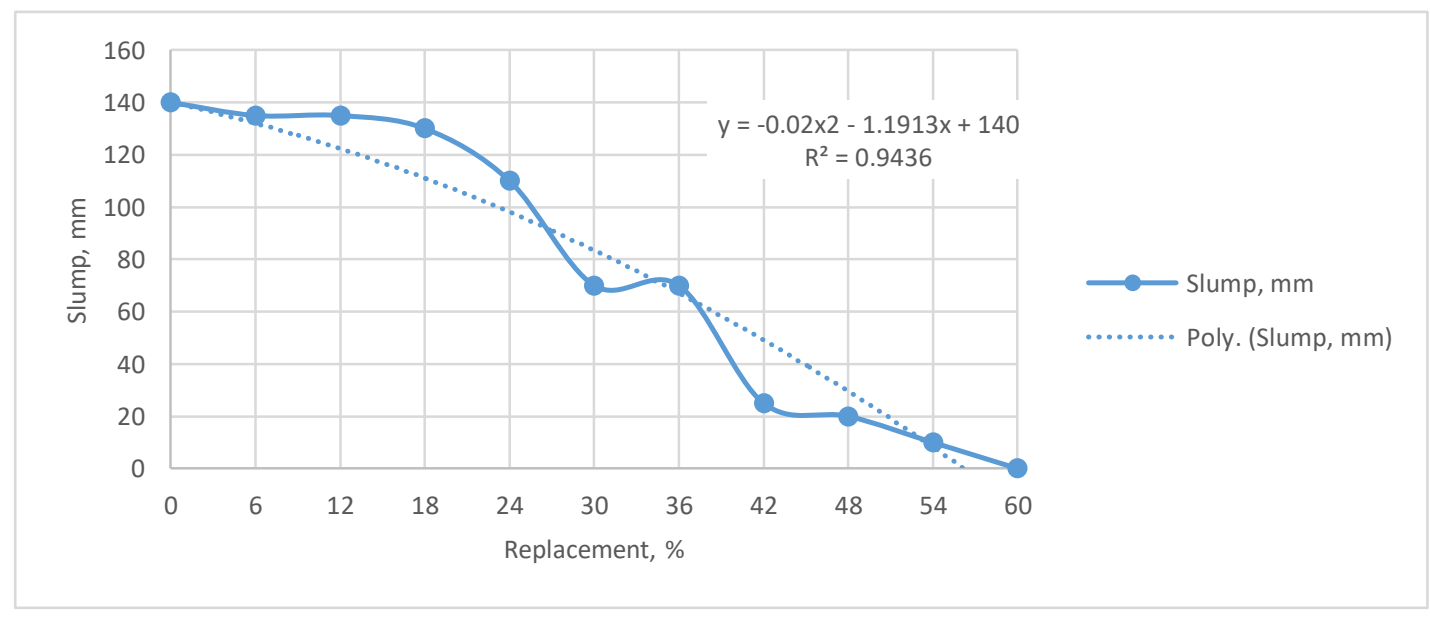

Fig. (2): Slump value versus rubber content

wrya.faraj@univsul.edu.iq; muhammad.rashid@univsul.edu.iq; mohamed.abdulkadir@univsul.edu.iq

${ }^{1}$ Corresponding author: College of Engineering, University of Sulaimani, Kurdistan Region, Iraq 
A polynomial equation can be proposed to predict the workability loss with respect to the percentage of sand replacement as given in Equation (1).

$$
y=-0.0231 x^{2}-1.1913 x+140
$$

Where $y$ represents the slump value in $\mathrm{mm}$ and $x$ is the percentage of fine aggregate replacement by mass. The equation estimates the slump value of rubberized concrete for some of the replacements. However, it underestimates the slump with $6,12,18$ and $60 \%$ of sand replacement. On the other hand, it overestimates the slump value for other sand replacement ratios.

After calculating the percentage of the slump reduction, it has been compared with the results of other previous studies in the literature such as Topc'u ad Demir (2007); Batayneh et al., (2008); Taha et al. (2008) and Ozbay et al., (2011). It can be noticed that rubber contents were measured by mass in the current study. Therefore, the replacement ratios have been converted to be counted by sand volume. This conversion has been done by multiplying the mass replacement by 2.3 based on the difference between the densities of sand and tire rubber. For instance, $60 \%$ of replacement by mass resulted in 138\% replacement by volume. Figure 3 presents the comparison of the percent reduction in slump with those reported by the past works. It is clear that the reduction in slumps increased with increasing the rubber content. The differences of values between all the studies mainly related to the water cement ratio and rubber particle sizes. It can be noticed that the slump reduction is less than $20 \%$ for the sand volumes replaced by up to $40 \%$ of tire rubber. From this replacement level upwards, the slump reduction increases significantly until it becomes $100 \%$ reduction at the sand replacement of $138 \%$ by volume.

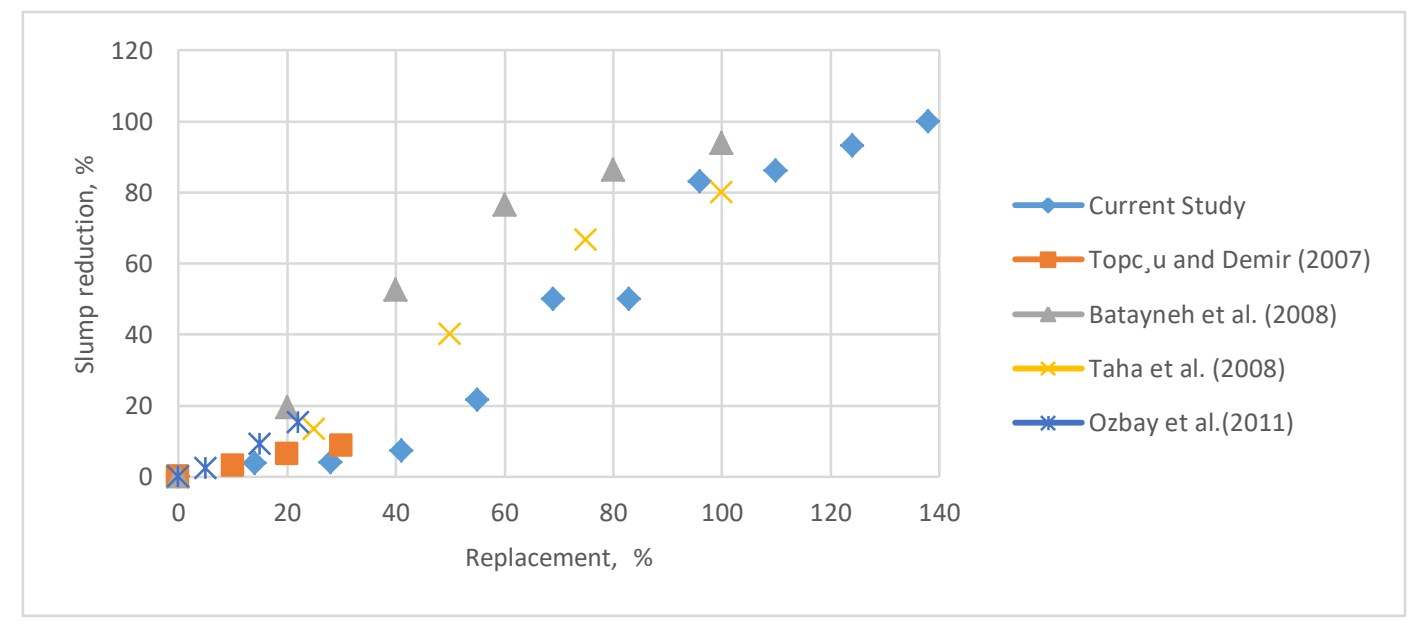

Fig. (3): Percent slump reduction versus rubber content

\subsection{Fresh Density}

The density of rubber is less than that of sand. Therefore, it is logical to conclude that the fresh density of the rubberized concrete decreases with an increase in amount of rubber content. It is observed that concrete can lose its density by wrya.faraj@univsul.edu.iq; mohamed.abdulkadir@univsul.edu.iq more than $17 \%$ if the amount of sand replacement with rubber chips reached $60 \%$ by mass. occurs while the increases in the concrete. A decline in fresh density can be seen from Figure 4 with an increase in the rubber replacement ratio. For instance, the fresh density muhammad.rashid@univsul.edu.iq;

${ }^{1}$ Corresponding author: College of Engineering, University of Sulaimani, Kurdistan Region, Iraq 
of the concrete is nearly $2260 \mathrm{~kg} / \mathrm{m}^{3}$ at zero rubber content, however it semi-linearly decreases to approximately $1770 \mathrm{~kg} / \mathrm{m}^{3}$ at $60 \%$ of rubber replacement. The reason behind this decrease is that the density of rubber is $576 \mathrm{~kg} /$ $\mathrm{m}^{3}$ which is only $43 \%$ of that of sand $(1322 \mathrm{~kg} /$ $\left.\mathrm{m}^{3}\right)$. As the reduction is linear, a linear equation can be proposed to estimate the fresh density of rubberized concrete based on the amount of replacement in the mix as given in Equation (2). $y=-7 x+2260$

Where $y$ represents the density of the mix in $\mathrm{kg} / \mathrm{m}^{3}$ and $x$ is the ratio of the sand replacement by rubber by mass. The equation can predict fresh density of rubberized in $\mathrm{kg} / \mathrm{m}^{3}$ concrete up to replacement rate of $60 \%$ by mass.

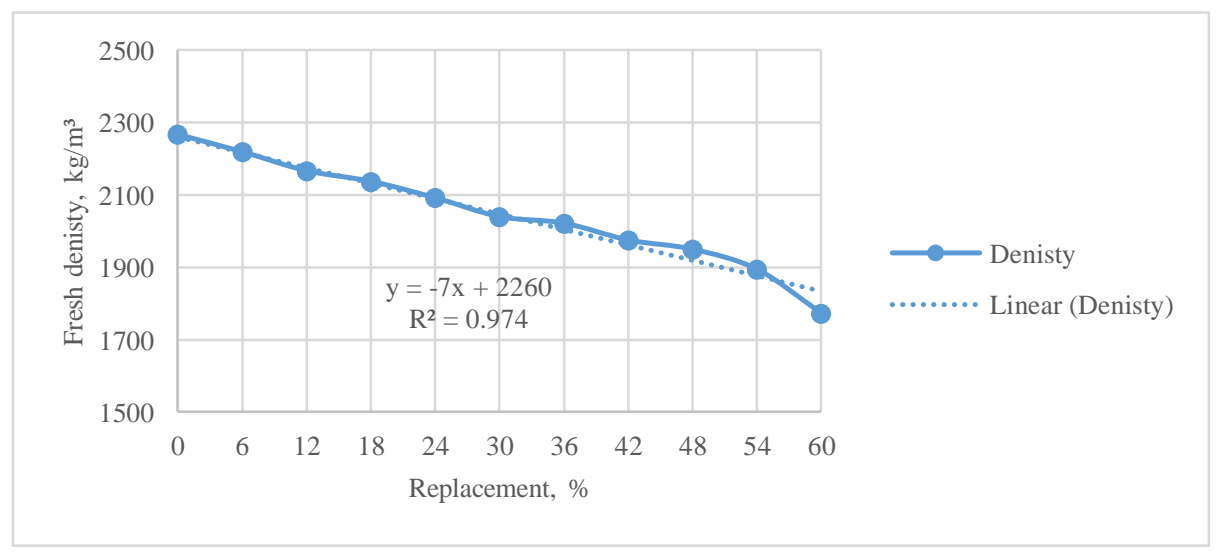

Fig. (4): Fresh density versus rubber content

These results are compared with those of various research groups found in the literature such as Mohammadi et al. (2014), Taha et al. (2008), Batayneh et al. (2008), Gridic et al. (2014) and Ozbay et al. (2011). It can be seen from Figure 5 that the pattern of increase in fresh density reduction is similar to the other results with a difference in the slope of trends. At the rubber level of $100 \%$ by volume, fresh density reduced up to $27.44 \%$ as reported by Batayneh et al. (2008) while it was only $22 \%$ in the current study. These differences in the percent of the reductions might be attributed to the reduction in water cement ratio and various aggregate densities used in both of the studies.

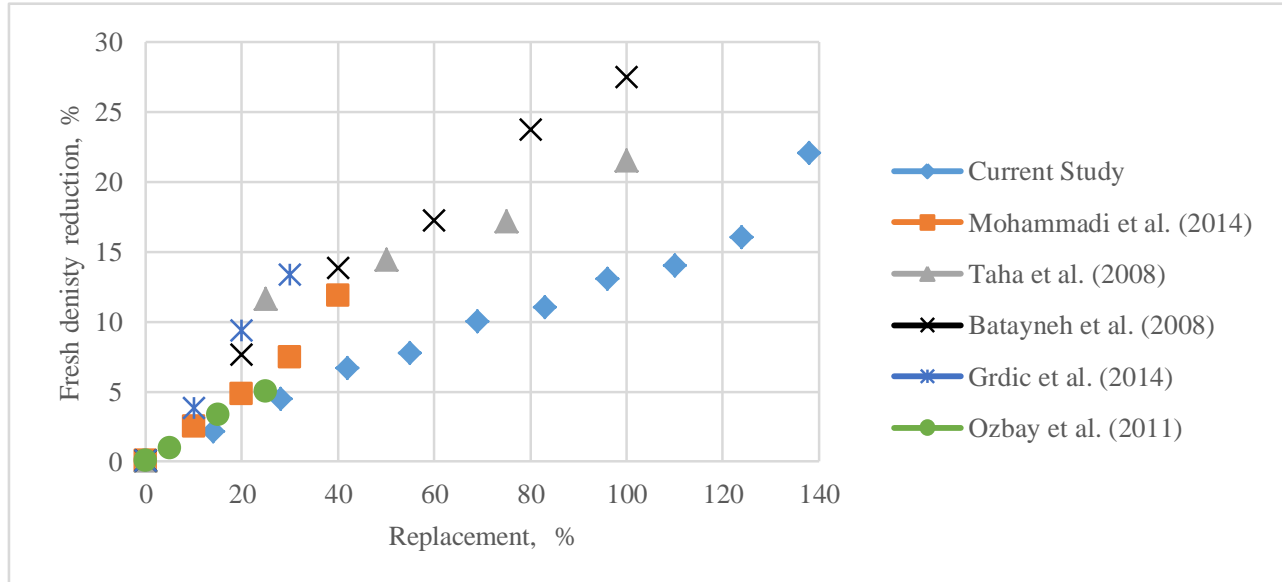

Fig. (5): Percent fresh density reduction versus rubber content

wrya.faraj@univsul.edu.iq; muhammad.rashid@univsul.edu.iq; mohamed.abdulkadir@univsul.edu.iq 


\subsection{Dry Density}

Density is indirectly proportioned with the percentage of rubber content in the concrete. Figure 6 shows a linear fall in dry density of the concrete samples as their rubber contents increase. It can be seen that the concrete had maximum dry density of $2300 \mathrm{~kg} / \mathrm{m}^{3}$ at $0 \%$ rubber in concrete while it reaches its minimum value of $1860 \mathrm{~kg} / \mathrm{m}^{3}$ at the rubber level of $60 \%$. This reduction is due to the fact that the specific gravity of the rubber is less than that of sand which was replaced with rubber. Equation (3) is proposed to count for that reduction in dry density of rubberized concrete based on the percentage of sand replacement.

$y=-7.75 x+2300$

Where $y$ represents the dry density of the rubberized concrete in $\mathrm{kg} / \mathrm{m}^{3}$ and $x$ represents the percentage of fine aggregate replacement. The equation can predict dry density with a great accuracy and without being conservative.

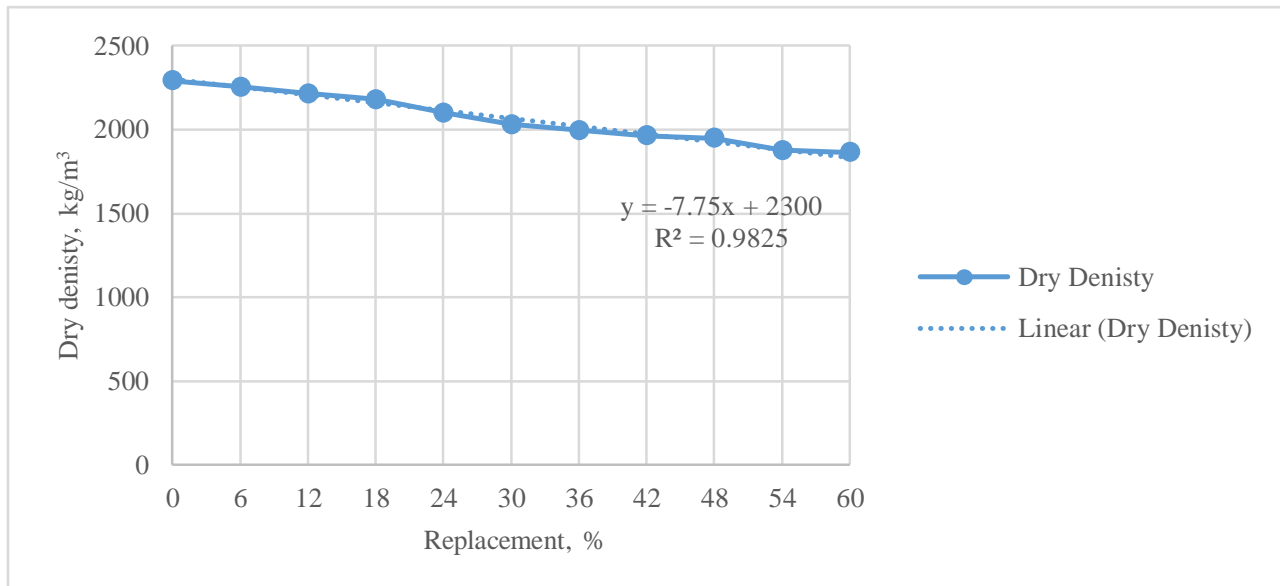

Fig. (6): Dry density versus rubber content

The percent mass loss was also calculated for all the samples and as it was expected the mass loss increases with an increase of rubber content because the presence of rubber with high percentages. Figure 7 shows semi-linear increase in the mass loss as the percentage of rubber content increases. The mass loss starts at zero percentage in control mix and rises to the maximum value of $18.4 \%$ at $60 \%$ rubber content.
Despite of this decrease in mass, it is proven that it resists impact loads to a satisfactory level (Muhammad et al., 2020). This mass loss has a great potential for using the rubberized concrete where density is not the main necessity. For instance, it can be used for precast units such as curbstones where impact resistance is the major requirement.

wrya.faraj@univsul.edu.iq; muhammad.rashid@univsul.edu.iq; mohamed.abdulkadir@univsul.edu.iq

${ }^{1}$ Corresponding author: College of Engineering, University of Sulaimani, Kurdistan Region, Iraq 


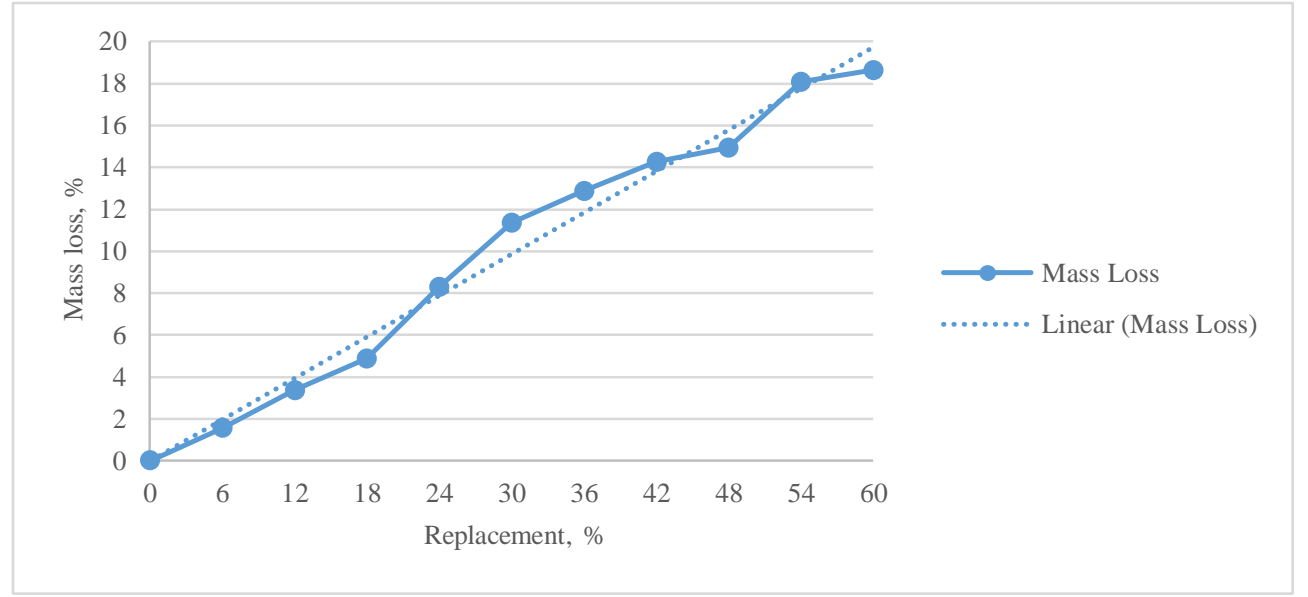

Fig. (7): Percent mass loss versus rubber content

Figure 8 shows the comparison of dry densities obtained from the current paper with those of the previous works in the literature done by Turki et al. (2009); Taha et al. (2008); Sukontasukkul and Tiamlom (2012); Gridic' et al. (2014); and Ling (2012). The results show that the dry density decreases with an increase of rubber content. The dry density reduction was under $20 \%$ at the majority of replacement levels. However, Turki et al. (2009) reported $22.3 \%$ reduction in the dry density when natural sand (size $2-0 \mathrm{~mm}$ ) was replaced with rubber made from shredded waste tires (size $4-1 \mathrm{~mm}$ ). A smooth- increase path can be observed from this study. The rate of increase is lower which might be because of the water to cement ratio which was lower compared to that used by the others. The main reason for these reduction in density can be attributed to different specific gravities of both natural fine aggregates and rubber chips.

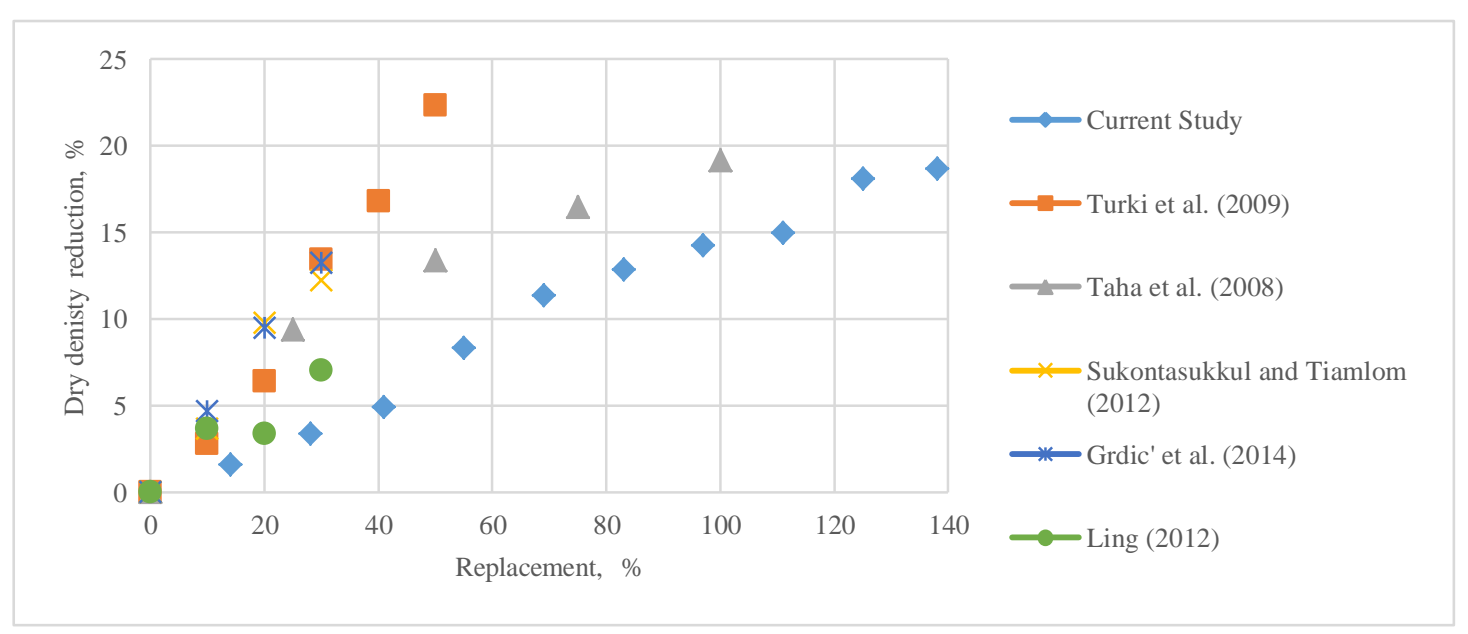

Fig. (8): Percent dry density reduction versus rubber content

\subsection{Compressive strength}

A considerable negative effects of tire rubber content on the compressive strength of the concrete can be seen in Figure 9. The compressive strength of the concrete decreases wrya.faraj@univsul.edu.iq; mohamed.abdulkadir@univsul.edu.iq

${ }^{1}$ Corresponding author: College of Engineering, University of Sulaimani, Kurdistan Region, Iraq with an increase in the rubber content. Rubber can be considered as a type of impurity; therefore, a reduction of compressive strength is a reasonable prediction. The compressive strength of the concrete dropped by $87 \%$ from muhammad.rashid@univsul.edu.iq;

adir@univsul.edu.iq 
$57 \mathrm{MPa}$ for control sample to $8 \mathrm{MPa}$ at $60 \%$ of rubber replacement as shown in Figure 9. The lower compressive strength of concrete can be useful in manufacturing masonry units for partition walls, constructing garden walkway and pavement (Gesoğlu et al., 2014). Test results of different studies showed that the particle size, surface texture and replacement ratio of tire rubber particles evidently affect compressive strength of rubberized concrete (Siddique \& Naik, 2004). The main reason of compressive strength reduction may relate to weak bond between the essential ingredients of the concrete and the rubber particles. The size of the rubber aggregate has undesirable effects in decreasing bond between the constituents of the concrete. The compressive strength of concrete was less affected by the smaller rubber particle size than the larger particle sizes. As the maximum size of the rubber chips was $4.75 \mathrm{~mm}$ which is considered to be large enough to decrease the bond. To count for this decrease of compressive strength with presence of rubber aggregate, a polynomial equation is proposed which can predict the compressive strength of rubberized concrete as given in Equation (4).

$$
y=0.01 x^{2}-1.35 x+55
$$

Where $y$ is the compressive strength of the concrete in MPa and $x$ is the percentage of sand replaced with rubber content by mass. The equation can predict the compressive strength accurately for normal compressive strengths of approximately $55 \mathrm{MPa}$.

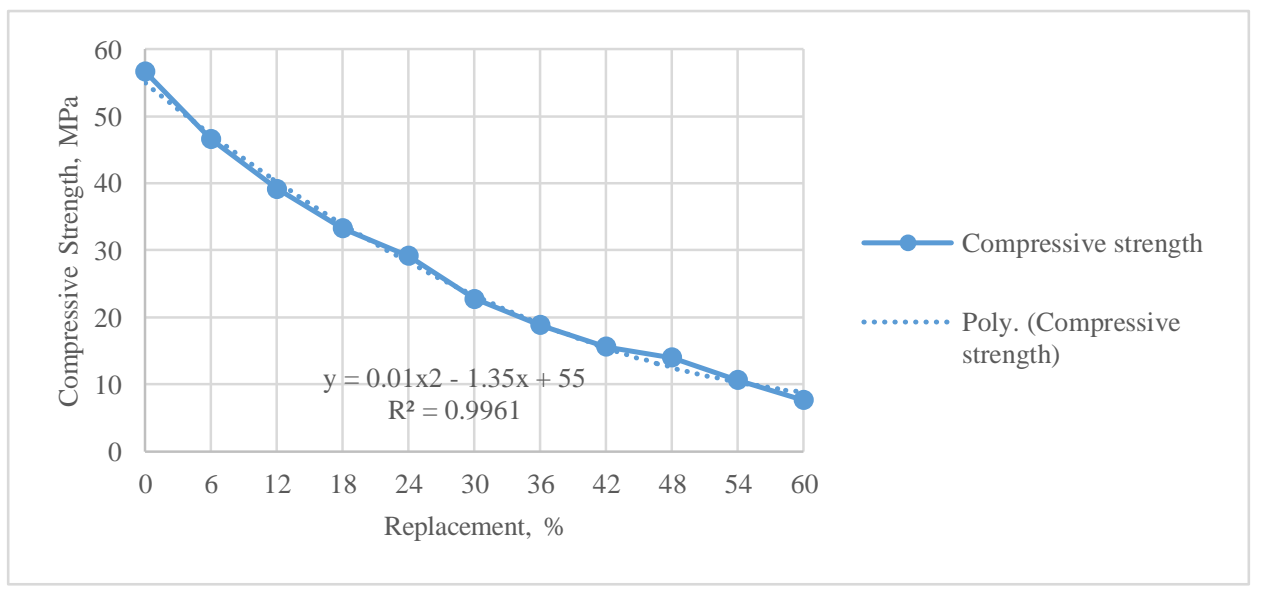

Fig. (9): Compressive strength versus rubber content

After that, a relationship between the percentages of sand replacement with percentage of compressive strength reduction is plotted as shown in Figure 10. Also, equation (5) is proposed for predicting the compressive strength reduction of the concrete which can predict it for any rage of replacement accurately.

$$
y=-0.02 x^{2}+2.6 x
$$

Where $y$ is the reduction of compressive strength of rubberized concrete in percentage and $x$ is the percentage of sand replacement with rubber.

wrya.faraj@univsul.edu.iq; muhammad.rashid@univsul.edu.iq; mohamed.abdulkadir@univsul.edu.iq 


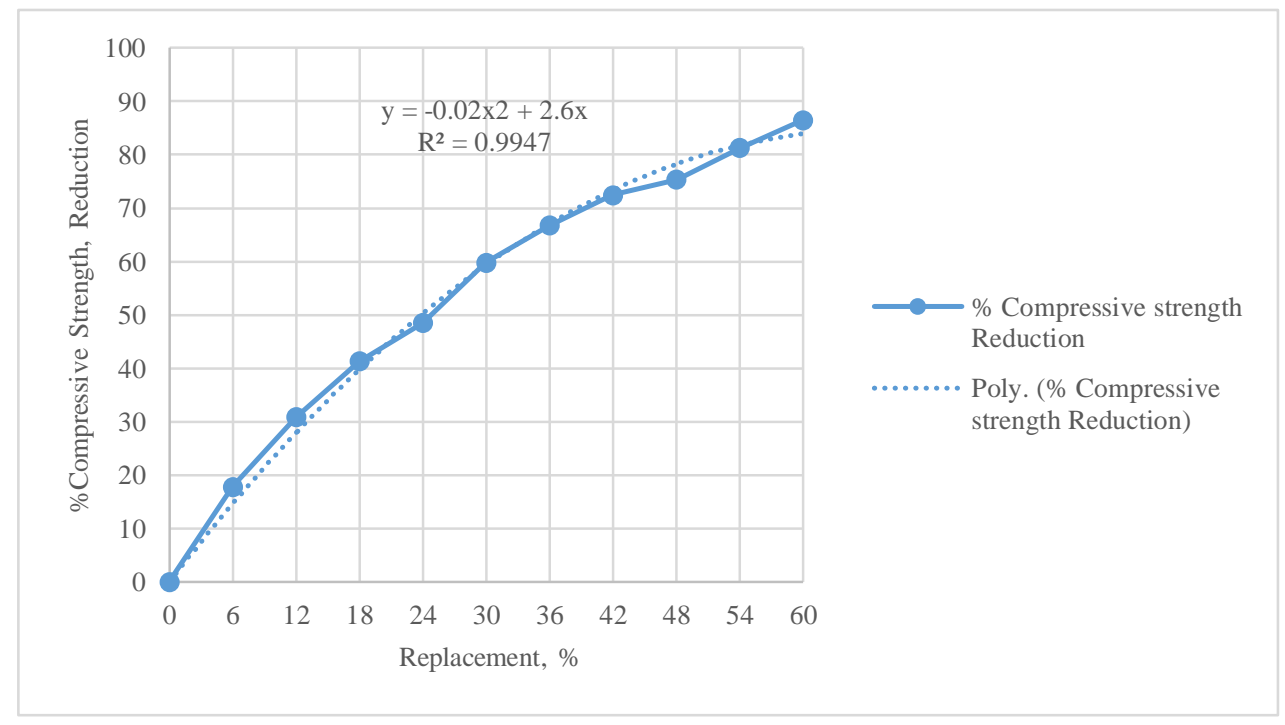

Fig. (10): Percent compressive strength reduction versus rubber content

After finding the percentage of reduction in compressive strength of the concrete, the results were compared with those of other researchers who fully replaced natural sand with tire rubber (Torgut and Yesilata 2008; Atahan \& Yücel, 2012; El-Gammal et al., 2010; Issa \& Salem, 2013; Khaloo et al., 2008; Taha et al., 2008). It can be seen from Figure 11 that the current study has more data with small increments of $6 \%$ until the full replacement, and the pattern is the smoothest among all. All of the research studies found out that the rubber content in concrete leads to a reduction of compressive strength with various ratios. Nearly all of them agreed that the reduction will be at its maximum when $100 \%$ of the sand is replaced with rubber. This reduction percentage varies from $67.4 \%$ found by Taha et al. (2008) to its maximum value of $98 \%$ reported by Khaloo et al. (2008). The current study found a total reduction of $73 \%$ where $100 \%$ of the volume of the sand is replaced by rubber. There are many factors affecting this variance such as maximum size of aggregate used in each investigation, and water to cement ratio which varies in the studies. It can, also, be noted that the reductions in compressive strength were less than $20 \%$ at up to the existence of $25 \%$ rubber content.

wrya.faraj@univsul.edu.iq; muhammad.rashid@univsul.edu.iq; mohamed.abdulkadir@univsul.edu.iq 


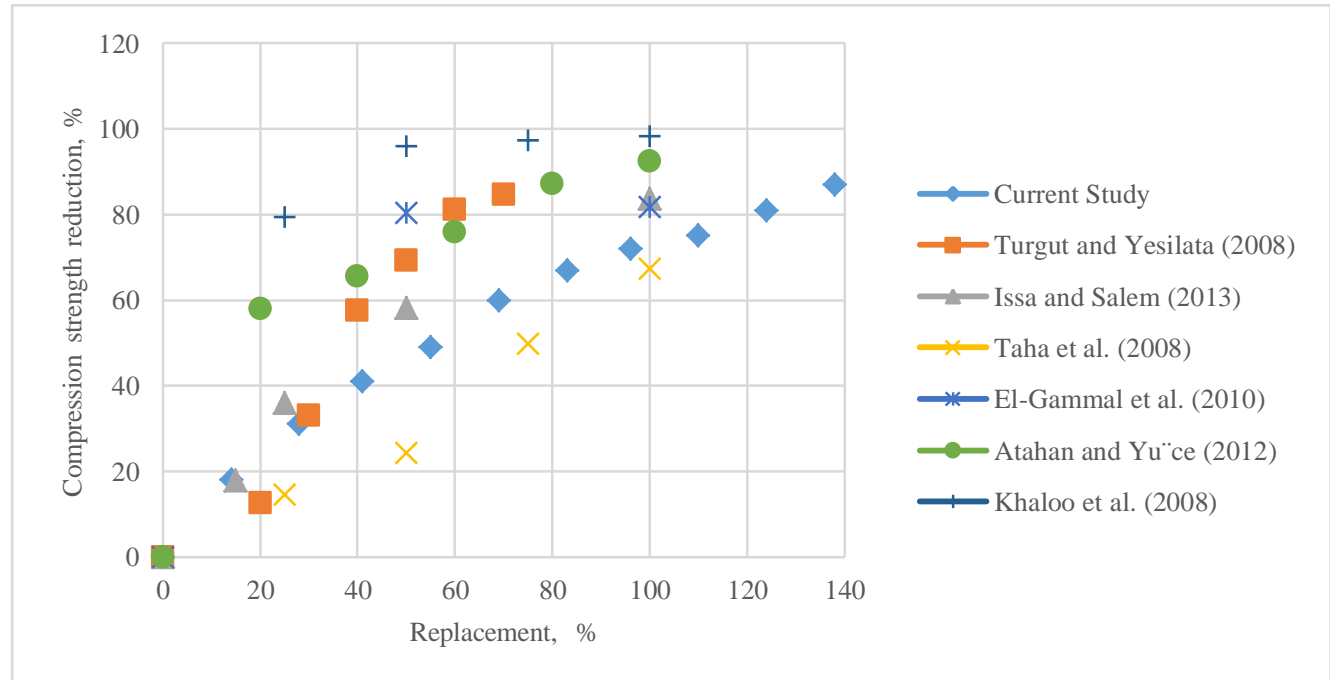

Fig. (11): Percent compressive strength reduction versus rubber content

\section{CONCLUSIONS}

After testing more than 11 different mixes of the concrete containing different ratios of rubber as a replacement of fine aggregate by mass and analyzing the results, the following conclusions can be drawn:

- The workability of rubberized concrete decreases with an increase of rubber content. For instance, the slump reduction percentage of the fresh rubberized concrete with $6 \%$ of fine aggregate replacement is only $3.75 \%$ while that number rises to $100 \%$ when $60 \%$ of the sand is replaced by rubber aggregate.

- The fresh density of the rubberized concrete decreases with an increase of rubber content. It semi-linearly decreases by $22 \%$ at $60 \%$ compared to the control mix. This reduction in fresh density is due to the difference in densities between the rubber and fine aggregate.

- The dry density of the rubberized concrete declines with an increase of rubber content. For example, concrete samples lost more than $18 \%$ of their masses after increasing the rubber content to $60 \%$ by mass.

- It was found that the rubberized concrete mixes were workable to a certain level of the sand replacement and resulted in lighter wrya.faraj@univsul.edu.iq; mohamed.abdulkadir@univsul.edu.iq concretes.

- The compressive strength of the concrete reduces with an increase of the replacement of the fine aggregate with rubber. The compressive strength reduction has reached $73 \%$ where the replacement ratio was $60 \%$ by mass.

- It can be concluded that using small increments of fine aggregate replacement with rubber chips has predictable values over large increments to investigate rubber content effects.

- According to the current and previous investigations, it has been found that the reductions in slump, dry density and compressive strength were less than $20 \%$ at replacement levels of $40 \%, 100 \%$ and $25 \%$ by volume, respectively.

\section{REFERENCES}

Abdullah, W. A., AbdulKadir, M. R., \& Muhammad, M. A. (2018). Effect of high temperature on mechanical properties of rubberized concrete using recycled tire rubber as fine aggregate replacement. Engineering and Technology Journal, 36(8 Part (A) Engineering), 906-913.

Atahan, A. O., \& Yücel, A. Ö. (2012). Crumb rubber in concrete: static and dynamic evaluation. Construction and Building

muhammad.rashid@univsul.edu.iq;

ity of Sulaimani, Kurdistan Region, Iraq 
Materials, 36, 617-622.

Batayneh, M. K., Marie, I., \& Asi, I. (2008). Promoting the use of crumb rubber concrete in developing countries. Waste Management, 28(11), 2171-2176.

Colom, X., Carrillo, F., \& Cañavate, J. (2007). Composites reinforced with reused tyres: Surface oxidant treatment to improve the interfacial compatibility. Composites Part A: Applied Science and Manufacturing, 38(1), 44-50.

Downard, J., Singh, A., Bullard, R., Jayarathne, T., Rathnayake, C. M., Simmons, D. L., ... \& Stanier, C. O. (2015). Uncontrolled combustion of shredded tires in a landfill-Part 1: Characterization of gaseous and particulate emissions. Atmospheric Environment, 104, 195-204.

El-Sherbini, Y., Abdel-Gawad, A. K., Shalaby, A., \& El-Gammal, A. (2010). Compressive strength of concrete utilizing waste tire rubber. Journal of Emerging Trends in Engineering and Applied Sciences, 1(1), 96-99.

EU. (1999). Council Directive 1999/31/EC of 26 April 1999 on the landfill of waste, OJ L 182, 16.7. 1999.

Gesoğlu, M., Güneyisi, E., Khoshnaw, G., \& İpek, S. (2014). Investigating properties of pervious concretes containing waste tire rubbers. Construction and Building Materials, 63, 206-213.

Grdić, Z., Topličić-Curčić, G., Ristić, N., Grdić, D., \& Mitković, P. (2014). Hydro-abrasive resistance and mechanical properties of rubberized concrete. Građevinar, 66(01.), 11-20.

Issa, C. A., \& Salem, G. (2013). Utilization of recycled crumb rubber as fine aggregates in concrete mix design. Construction and wrya.faraj@univsul.edu.iq; muhammad.rashid@univsul.edu.iq; mohamed.abdulkadir@univsul.edu.iq

${ }^{1}$ Corresponding author: College of Engineering, University of Sulaimani, Kurdistan Region, Iraq
Building Materials, 42, 48-52.

Khaloo, A. R., Dehestani, M., \& Rahmatabadi, P. (2008). Mechanical properties of concrete containing a high volume of tire-rubber particles. Waste Management, 28(12), 2472 2482.

Ling, T. C. (2012). Effects of compaction method and rubber content on the properties of concrete paving blocks. Construction and Building Materials, 28(1), 164-175.

Mohammadi, I., Khabbaz, H., \& Vessalas, K. (2014). In-depth assessment of Crumb Rubber Concrete (CRC) prepared by water-soaking treatment method for rigid pavements. Construction and Building Materials, 71, 456-471.

Muhammad, M. A., Faraj, W. A. A \& Abdul-Kadir, M. R. (2020). Effect of Impact Load on Concrete Containing Recycled Tire Rubber Aggregate with and without Fire Exposure. Kurdistan Journal of Applied Research, 5(1), 49-65.

Muhammad, M., Abdullah, W., \& Abdul-Kadir, M. (2017). Post-fire mechanical properties of concrete made with recycled tire rubber as fine aggregate replacement. Sulaimani Journal for Engineering Sciences, 4(5), 74-85.

Ozbay, E., Lachemi, M., \& Sevim, U. K. (2011). Compressive strength, abrasion resistance and energy absorption capacity of rubberized concretes with and without slag. Materials and Structures, 44(7), 1297-1307.

Pacheco-Torgal, F., Ding, Y., \& Jalali, S. (2012). Properties and durability of concrete containing polymeric wastes (tyre rubber and polyethylene terephthalate bottles): An overview. Construction and Building Materials, 30, 714-724.

Reda Taha, M. M., El-Dieb, A. S., Abd El-Wahab, M. A., \& Abdel-Hameed, M. E. (2008). 
Mechanical, fracture, and microstructural investigations of rubber concrete. Journal of materials in civil engineering, 20(10), 640-649.

Rubber Manufacturers Association. (2018). 2017 U.S. Scrap Tire Management Summary.

Siddique, R., \& Naik, T. R. (2004). Properties of concrete containing scrap-tire rubber-an overview. Waste management, 24(6), 563-569.

Sukontasukkul, P., \& Tiamlom, K. (2012). Expansion under water and drying shrinkage of rubberized concrete mixed with crumb rubber with different size. Construction and Building Materials, 29, 520-526.

Topçu, İ. B., \& Demir, A. (2007). Durability of rubberized mortar and concrete. Journal of materials in Civil Engineering, 19(2), 173-178.

Turgut, P., \& Yesilata, B. (2008). Physico-mechanical and thermal performances of newly developed rubber-added bricks. Energy and Buildings, 40(5), 679-688.

Turki, M., Bretagne, E., Rouis, M. J., \& Quéneudec, M. (2009). Microstructure, physical and mechanical properties of mortar-rubber aggregates mixtures. Construction and Building Materials, 23(7), 2715-2722. 